\title{
Role of Fine Needle Aspiration, Intraoperative Imprint Cytology and Frozen Section in the Diagnosis of Breast Lumps and Thyroid Lesions
}

\author{
Issam M. Francis Dilip K. Das \\ Cytology and Histopathology Units, Mubarak Al-Kabeer Hospital Kuwait, and \\ Department of Pathology, Faculty of Medicine, Kuwait University, Kuwait
}

\section{Key Words}

Fine needle aspiration cytology · Imprint cytology · Frozen section · Intraoperative cytology · Thyroid · Breast · Follicular neoplasm $\cdot$ Papillary carcinoma $\cdot$ Ductal carcinoma

\begin{abstract}
Background and Objectives: Lesions of the thyroid and breast represent the two commonest sources of frozen section in Kuwait. This study investigates the value of intraoperative cytology (IC), preoperative fine needle aspiration cytology (FNAC) and intraoperative frozen section (FS), in improving the diagnostic accuracy of such lesions. Material: Thirty-one breast masses and 45 thyroid lesions were included. Methods: In each case, diagnosis was established by (1) preoperative FNAC, (2) intraoperative IC and (3) FS. Their accuracy was compared to paraffin section diagnosis. Results: Sensitivity of FNAC, IC and FS for breast malignancy was 82.6,
\end{abstract}

95.8 and $91.7 \%$, respectively, while for thyroid malignancy sensitivity was $68.4,85.0$ and $65 \%$, respectively. All three had $100 \%$ specificity and $0 \%$ false-positive rates. A $100 \%$ diagnostic accuracy was achieved by combined FNAC and IC in breast, and 93.3\% with combined IC and FS in thyroid lesions. Conclusion: Intraoperative IC improves the diagnostic accuracy of FNAC and FS in breast and thyroid lesions.

\section{Introduction}

Fine needle aspiration cytology (FNAC) has been used extensively over the years for the investigation of breast masses and thyroid nodules. However, despite the high success rate of FNAC in preoperative evaluation, there remains a significant group of thyroid nodules for which the results are either suspicious or indeterminate $[1,2]$. This technique is also not uniformly successful in separating

\begin{tabular}{ll}
\hline KARGER & (1) 1999 S. Karger AG, Basel \\
Fax +41 61306 1234 $34-7571 / 99 / 0083-0173 \$ 17.50 / 0$ \\
$\begin{array}{l}\text { E-Mail karger@karger.ch } \\
\text { www.karger.com }\end{array}$ & $\begin{array}{l}\text { Accessible online at: } \\
\text { http://BioMedNet.com/karger }\end{array}$
\end{tabular}

Dr. Issam M. Francis

Department of Pathology, Faculty of Medicine

Kuwait University, PO Box 24923

13110 Safat (Kuwait)

Fax+965 533 8905, E-Mail issam@hsc.kuniv.edu.kw 
Table 1. Correlation of FNAC, IC and FS diagnosis of breast lesions with permanent paraffin section diagnosis

\begin{tabular}{|c|c|c|c|c|}
\hline $\begin{array}{l}\text { Histopathological } \\
\text { diagnosis (paraffin section) }\end{array}$ & Cases & FNAC diagnosis & IC & FS diagnosis \\
\hline $\begin{array}{l}\text { Ductal Ca. }^{\text {a }} \\
\text { Ductal Ca. } \\
\text { Ductal Ca. } \\
\text { Ductal Ca. } \\
\text { Ductal Ca. } \\
\text { Lobular Ca. }^{\text {a }} \\
\text { Ductal Ca. in situ } \\
\text { Ductal Ca. in situ } \\
\text { Fibroadenoma } \\
\text { Fibroadenosis } \\
\text { Mastitis }\end{array}$ & $\begin{array}{r}16 \\
1 \\
1 \\
1 \\
1 \\
2 \\
1 \\
1 \\
3 \\
3 \\
1\end{array}$ & $\begin{array}{l}\text { ductal Ca. } \\
\text { ? ductal Ca. } \\
\text { atypia }^{\mathrm{b}} \\
\text { benign lesion } \\
\text { nondiagnostic } \\
\text { lobular Ca. } \\
\text { carcinoma } \\
\text { atypiab }^{\mathrm{b}} \\
\text { fibroadenoma } \\
\text { fibroadenosis } \\
\text { benign lesion }\end{array}$ & $\begin{array}{l}\text { ductal Ca. } \\
\text { ductal Ca. } \\
\text { ductal Ca. } \\
\text { ductal Ca. } \\
\text { ductal Ca. } \\
\text { lobular Ca. } \\
\text { inflammation } \\
\text { carcinoma } \\
\text { fibroadenoma } \\
\text { fibroadenosis } \\
\text { inflammation }\end{array}$ & $\begin{array}{l}\text { ductal Ca. } \\
\text { ductal Ca. } \\
\text { ductal Ca. } \\
\text { ductal Ca. } \\
\text { ductal Ca. } \\
\text { lobular Ca. } \\
\text { inflammation } \\
\text { ? Ca. in situa } \\
\text { fibroadenoma } \\
\text { fibroadenosis } \\
\text { inflammation }\end{array}$ \\
\hline \multicolumn{5}{|c|}{$\begin{array}{l}\text { a Complete agreement between four parameters. } \\
\text { b Cases regarded as false negative in statistical analysis of sensitivity and specificity. } \\
\text { c Nondiagnostic cases excluded from statistical analysis of sensitivity, specificity and diag- } \\
\text { nostic accuracy. }\end{array}$} \\
\hline
\end{tabular}

follicular adenomas from follicular carcinoma and in identifying some papillary carcinomas [3]. The decision about the extent of thyroidectomy may be difficult in these cases. Similarly, the exact role of FNAC in the diagnosis of palpable breast lesions is still uncertain [4]. There are authors who advocate that mastectomy be performed solely based on cytology reports [5-7], whereas others advise frozen section (FS) confirmation $[8,9]$. According to Silverman et al. [10], by utilizing FNAC biopsy with FS confirmation in a specific situation a more accurate diagnosis can be offered with virtual elimination of false-positive diagnosis and, thereby, unnecessary mastectomies. Intraoperative imprint cytology has also emerged as an important diagnostic adjunct to FS in benign and malignant lesions of various body sites as revealed in a review of the literature by Kontozoglou and Cramer [11].

In the present study we have included 31 cases with palpable breast masses and 45 thyroid lesions, where preoperative FNAC and intraoperative diagnostic procedures such as imprint cytology (IC) and FS were performed. The sensitivity, specificity and diagnostic accuracy of these techniques as compared to final histological diagnosis on paraffin section are evaluated.

\section{Materials and Methods}

Thirty-one patients with breast masses and 45 patients with thyroid lesions were subjected to preoperative FNAC and intraoperative IC and FS at Mubarak Al-Kabeer Hospital, Kuwait during a period of 2 years (1991-1992).

The ages of the 31 patients with breast masses ranged from 18 to 60 years with a median of 45 years. Male:female ratio was 2:29. Preaspiration clinical diagnosis was breast mass in 28 cases and breast mass with suspicion of malignancy in 3 cases. The ages of the 45 patients with thyroid lesions ranged from 19 to 63 years with a median of 37 years. Male:female ratio was $4: 41$. Preaspiration clinical/scintiscan diagnosis was cold nodule in 31 cases, solitary nodule in 2 cases, goiter/multinodular goiter in 10 cases, and thyrotoxicosis/hyperthyroidism in 2 cases. 


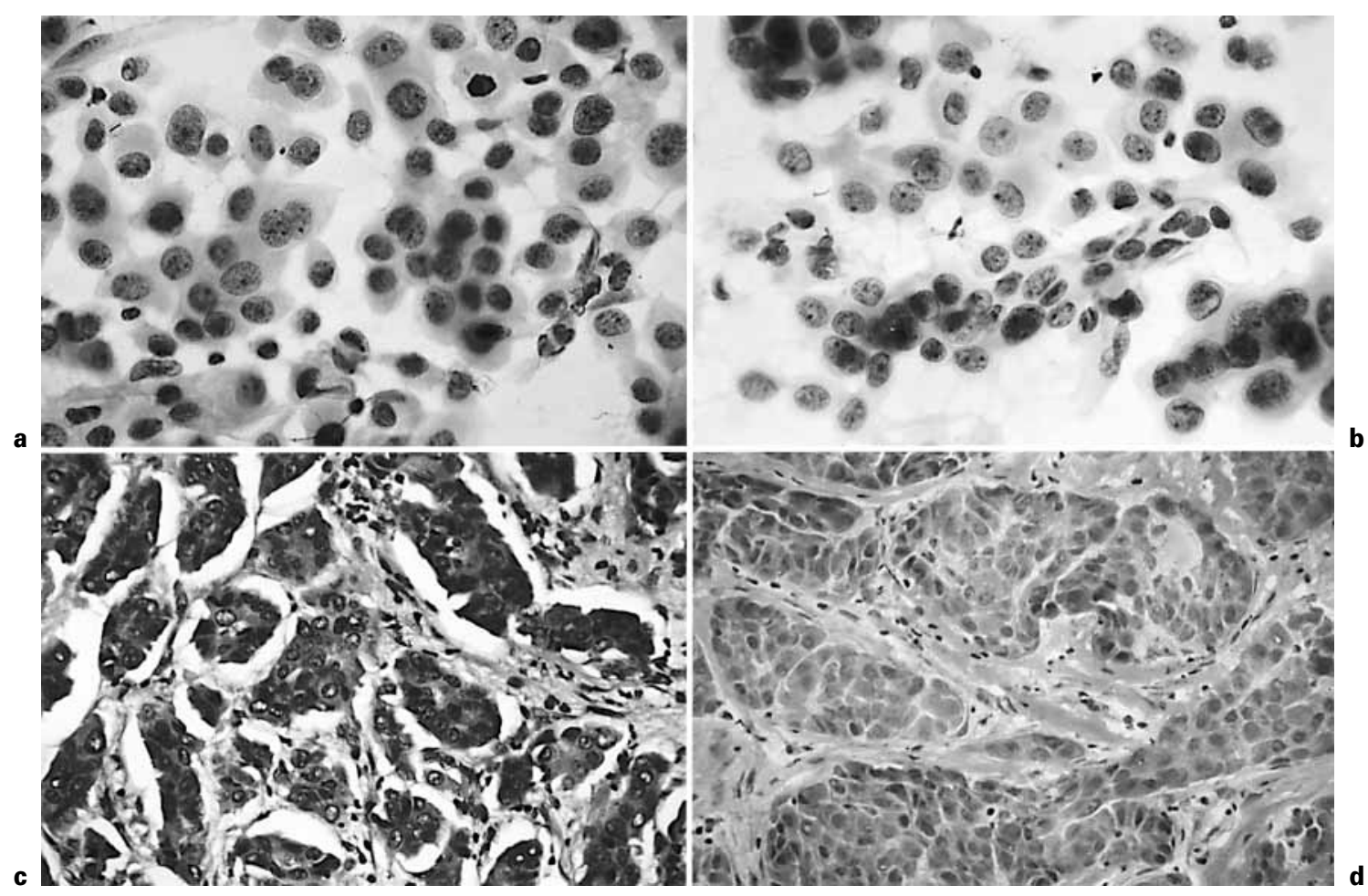

b

Fig. 1. Duct cell carcinoma in the breast of a 51-year-old-female. a FNAC smear showing groups of loosely cohesive malignant cells with small nucleoli. HE. $\times 400$. b IC smear showing malignant duct cells. HE. $\times 400$. c FS showing islands of malignant cells. HE. $\times 200$. d Paraffin section showing infiltrating groups of malignant cells showing glandular formation at places. HE. $\times 200$.

FNAC was performed with 10 -ml disposable plastic syringes and 22- to 23-gauge disposable needles fitted with Cameco-syringe handle. The smears were routinely stained by May-Grünwald-Giemsa (MGG) stain and hematoxylin and eosin (HE) stain. Malignancy was detected in 19 cases with breast masses, 1 was suspected to be malignant, 2 showed cytological atypia, 8 were benign and 1 sample was nondiagnostic. The indication for FS was either to confirm the cytodiagnosis and/or estrogen receptor study. Amongst thyroid lesions 11 cases were malignant; 12 were either follicular neoplasm or Hürthle cell adenoma, and was hyperplastic nodule/follicular adenoma, 17 were nonneoplastic benign lesions and 4 were nondiagnostic. The indication for FS was done either to confirm the cytodiagnosis or rule out malignancy.

During surgery, either imprint or crush smears were prepared from the FS biopsy and stained by MGG as well as HE stain. Frozen sections were stained

Diagnosis of Breast Lumps and Thyroid Lesions by HE stain. After surgery the resected tumors or biopsies were processed for paraffin sections and routinely stained by HE stain.

The diagnoses obtained by FNAC, intraoperative IC and FS were compared with those of permanent paraffin sections. The sensitivity, specificity, false-negative rate, false-positive rate for breast and thyroid malignancies were found out using appropriate formulae $[12,13]$. The overall diagnostic accuracy of FNAC, IC and FS for specific type of benign and malignant breast and thyroid lesions were also found out.

\section{Results}

Table 1 shows correlation between diagnoses of breast lesions obtained from FNAC, intraoperative IC and FS and that of paraffin 


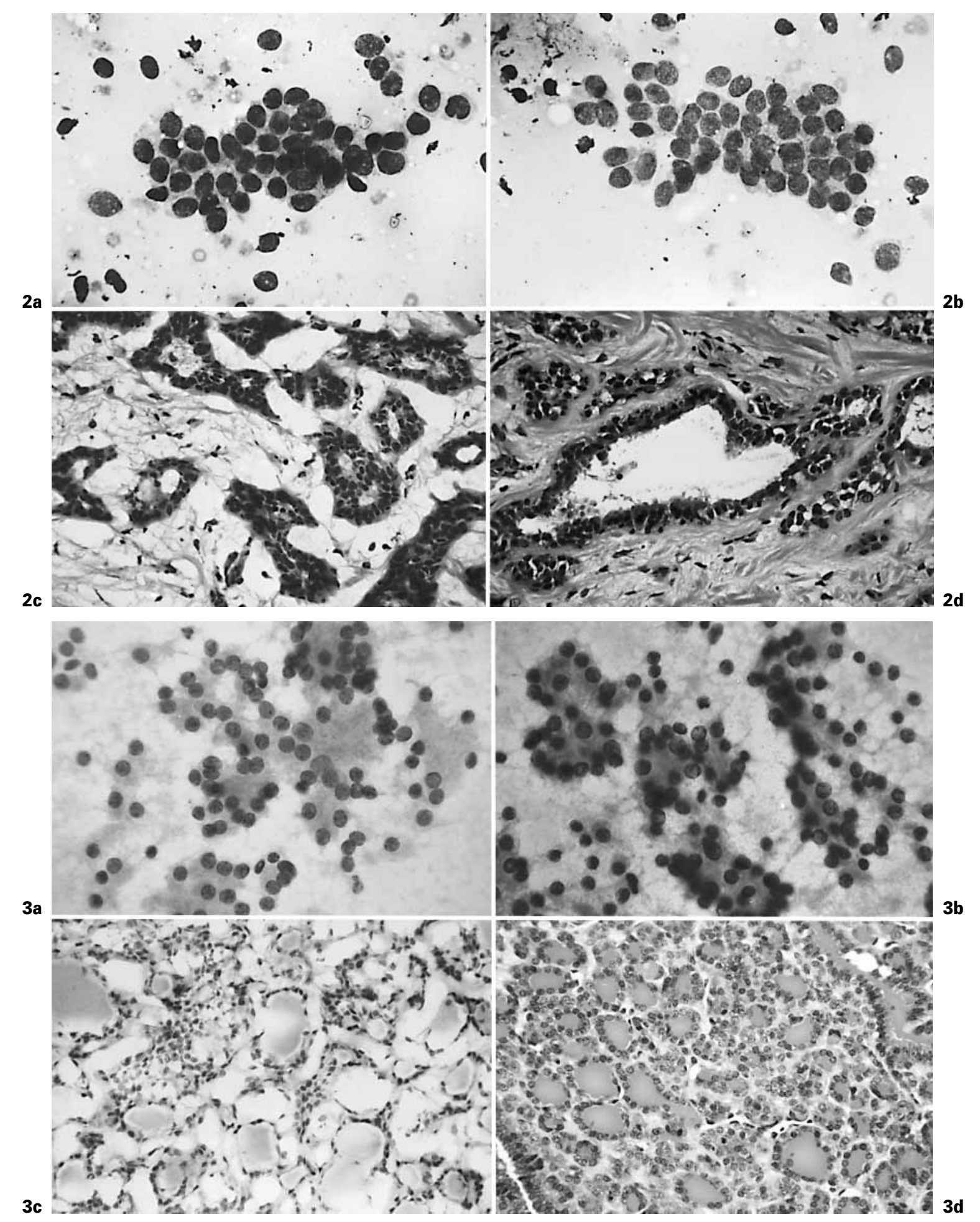


Table 2. Correlation of FNAC, IC and FS diagnosis of thyroid lesions with permanent paraffin section diagnosis

\begin{tabular}{|c|c|c|c|c|}
\hline $\begin{array}{l}\text { Histopathological } \\
\text { diagnosis (paraffin section) }\end{array}$ & Cases & FNAC diagnosis & IC & FS diagnosis \\
\hline Follicular adenoma ${ }^{\mathrm{a}}$ & 4 & follicular neoplasm & follicular neoplasm & follicular adenoma \\
\hline Follicular adenoma & 3 & follicular neoplasm & benign lesion & follicular adenoma \\
\hline Follicular adenoma & 6 & colloid goiter & colloid goiter & follicular adenoma \\
\hline Follicular adenoma & 1 & nondiagnostic ${ }^{b}$ & follicular neoplasm & follicular adenoma \\
\hline Follicular adenoma & 1 & Hürthle-cell neoplasm & colloid goiter & follicular adenoma \\
\hline Papillary carcinoma ${ }^{\mathrm{a}}$ & 11 & papillary $\mathrm{Ca}$. & papillary $\mathrm{Ca}$. & papillary $\mathrm{Ca}$. \\
\hline Papillary Ca. (occult) & 1 & follicular neoplasm & follicular neoplasm & nondiagnostic ${ }^{b}$ \\
\hline Hürthle-cell neoplasm and papillary $\mathrm{Ca}$. & 1 & Hürthle-cell neoplasm & $\begin{array}{l}\text { Hürthle-cell neoplasm } \\
\text { and papillary Ca. }\end{array}$ & thyroiditis \\
\hline Hürthle-cell neoplasm and papillary $\mathrm{Ca}$. & 1 & Hürthle-cell neoplasm & Hürthle-cell adenoma & Hürthle-cell adenoma \\
\hline Papillary Ca. (follicular variant) & 1 & benign lesion & papillary carcinoma & follicular adenoma \\
\hline Papillary Ca. (follicular variant) & 1 & hyperplastic nodule & papillary carcinoma & follicular adenoma \\
\hline Papillary Ca. & 1 & benign lesion & papillary carcinoma & deferred \\
\hline Papillary Ca. (occult) & 1 & nondiagnostic ${ }^{b}$ & hyperplasia & hyperplasia \\
\hline Medullary Ca. ${ }^{\mathrm{a}}$ & 1 & medullary carcinoma & medullary carcinoma & medullary carcinoma \\
\hline Centroblastic NHL & 1 & NHL & NHL & malignant tumor \\
\hline Colloid goiter ${ }^{\mathrm{a}}$ & 5 & colloid goiter & colloid goiter & colloid goiter \\
\hline Colloid goiter & 2 & benign lesion & colloid goiter & colloid goiter \\
\hline Colloid goiter & 1 & Hürthle-cell neoplasm & colloid goiter & colloid goiter \\
\hline Colloid goiter & 2 & nondiagnostic ${ }^{b}$ & colloid goiter & colloid goiter \\
\hline
\end{tabular}

a Complete agreement between four parameters.

b Nondiagnostic cases excluded from statistical analysis of sensitivity and specificity.

section. In 16 cases of duct cell carcinoma (fig. 1), 2 cases of lobular carcinoma, 3 cases of fibroadenoma and 3 cases of fibroadenosis (fig. 2) there was complete agreement among the four parameters. Of the remaining 9 cases,

Fig. 2. Fibroadenosis of the right breast in a 27 -yearold female. a FNAC smear shows a group of benign monomorphic ductular cells and a few bipolar cells. MGG. $\times 400$. b IC showing similar morphology as FNAC smear. MGG. $\times 400$. c FS showing benign glands surrounded by fibrocollagenous tissue. HE. $\times 200$. d Paraffin section confirms the cytodiagnosis of fibroadenosis. HE. $\times 200$.

Fig. 3. Follicular adenoma of thyroid in a 31 -year-old female. a FNAC smear shows microacinar formation by follicular cells. HE. $\times 400$. b IC shows similar morphology as FNAC smear. HE. $\times 400$. c FS shows follicles of almost uniform size. HE. $\times 200$. d Paraffin section shows typical histologic picture of follicular adenoma. There was no capsular or vascular invasion. HE. $\times 200$.

Diagnosis of Breast Lumps and

Thyroid Lesions there was agreement among three parameters in 7 cases and between two parameters in 2 cases.

Table 2 shows the correlation of FNAC, intraoperative IC and FS with the diagnosis obtained from permanent paraffin sections. In 4 cases of follicular adenoma (fig. 3), 11 cases of papillary carcinoma (fig. 4), 1 case of medullary carcinoma (fig. 5) and 5 cases of colloid goiter there was complete agreement among four parameters. Of the remaining 24 cases there was agreement among three parameters in 11 cases and between two parameters in 10 cases. The remaining 3 cases, which were histologically diagnosed as occult papillary carcinoma, could not be diagnosed by FNAC, IC or FS.

Sensitivity, specificity, false-positive and false-negative rates of malignancies of breast and thyroid are shown in table 3 . Sensitivity

Med Principles Pract 1999;8:173-182 


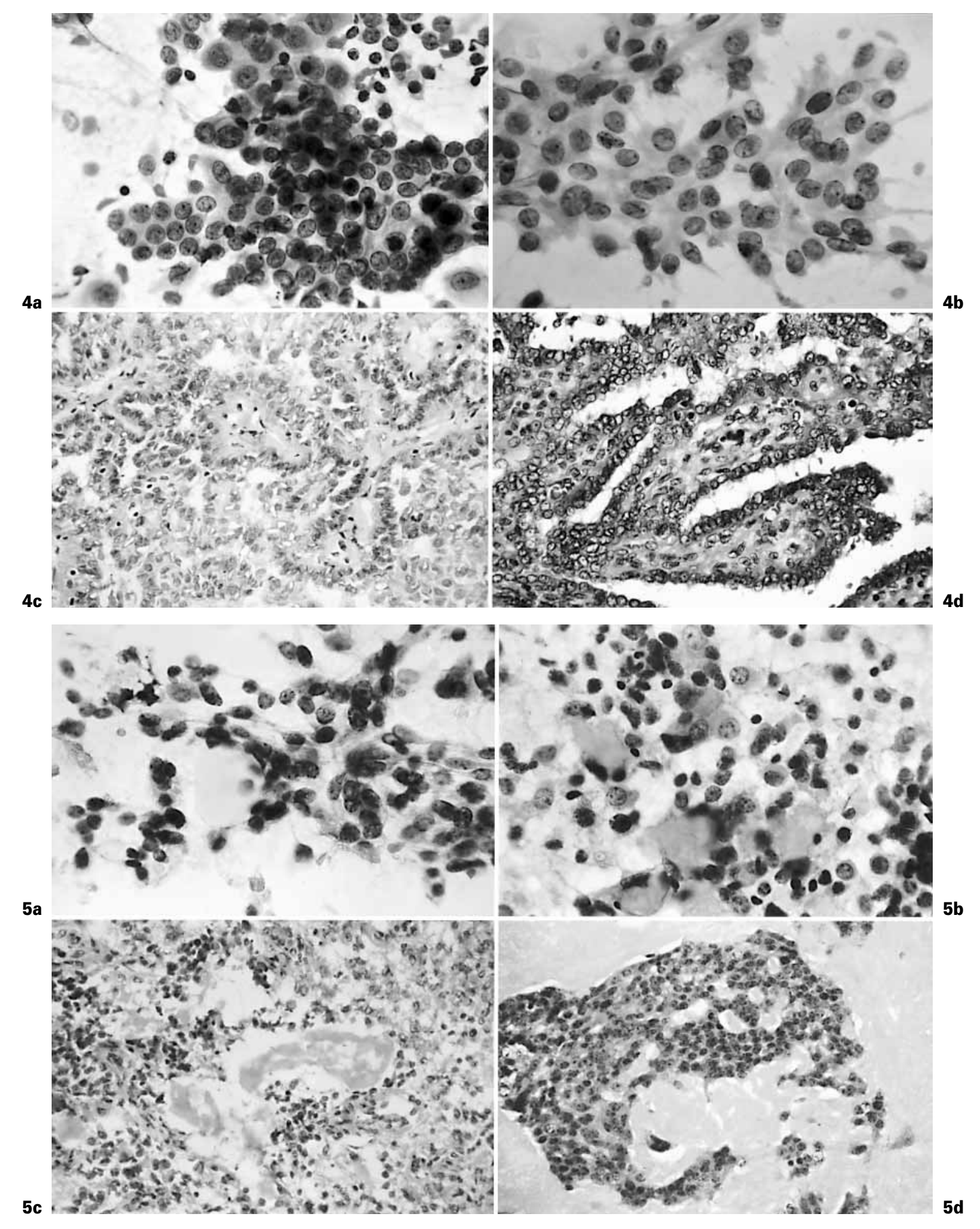


Table 3. Sensitivity, specificity, false-positive rate and falsenegative rate of FNAC, IC and FS in malignancies of breast and thyroid

\begin{tabular}{lrrrrrrrr}
\hline \multirow{2}{*}{ Parameter } & \multicolumn{3}{c}{ Breast $(\mathrm{n}=24)$} & & \multicolumn{3}{c}{ Thyroid $(\mathrm{n}=20)$} \\
\cline { 2 - 4 } \cline { 7 - 8 } & FNAC & IC & \multicolumn{1}{c}{ FS } & & FNAC & IC & \multicolumn{1}{c}{ FS } \\
\hline Sensitivity & 82.6 & 95.8 & 91.7 & & 68.4 & 85.0 & 65 \\
Specificity & 100.0 & 100.0 & 100.0 & & 100.0 & 100.0 & 100.0 \\
False positive & 0.0 & 0.0 & 0.0 & & 0.0 & 0.0 & 0.0 \\
False negative & 17.4 & 4.1 & 8.3 & & 31.5 & 15 & 31.5 \\
\hline
\end{tabular}

Values are expressed in percentages. There were 31 breast and 45 thyroid lesions. Samples were nondiagnostic in 1 breast FNA, 4 thyroid FNA and 1 thyroid FS and were excluded from statistical analysis of sensitivity, specificity and diagnostic accuracy. of FNAC, IC and FS for malignancies of the breast was $82,95.8$ and $91.7 \%$, respectively. The sensitivity of FNAC, IC and FS for thyroid malignancies was $68.4,85.0$ and $65 \%$, respectively. Specificity was $100 \%$ and falsepositive rates were $0 \%$ for all three parameters for both breast and thyroid malignancies. False-negative rates of FNAC, IC and FS for breast and thyroid lesions ranged from 4.1 to $17.4 \%$ and 15 to $31.5 \%$, respectively.

The overall diagnostic accuracy of FNAC, IC and FS individually and in various combinations for specific types of benign and malig-

Fig. 4. Papillary carcinoma of thyroid in the left lobe of a 29-year-old female. a FNAC smear shows a sheet of neoplastic cells with well-defined thick cytoplasm and irregular nuclei with grooves (arrowhead). HE. $\times 400$. b Intraoperative IC showing similar morphology as a FNAC smear. HE. $\times 400$. c FS shows papillary processes. HE. $\times 200$. d Paraffin section shows papillary processes and optically clear nuclei. HE. $\times 200$.

Fig. 5. Medullary carcinoma of thyroid in a 44-yearold male. a FNAC smear shows dispersed spindled and polygonal cells surrounding globules of hyaline material. b Intraoperative IC showing identical morphology to FNAC. c FS shows sheets of cells around hyaline material. d Paraffin section confirms the diagnosis of medullary carcinoma. The hyaline deposits noted in a-c stained positive for amyloid.

Diagnosis of Breast Lumps and

Thyroid Lesions
Table 4. FNAC, IC and FS in the diagnosis of breast and thyroid lesions: overall diagnostic accuracy for specific types of benign and malignant lesions

\begin{tabular}{lcc}
\hline Parameter & \multicolumn{2}{c}{ Overall diagnostic accuracy } \\
\cline { 2 - 3 } & breast & thyroid \\
\hline FNAC & 83.3 & 63.4 \\
IC & 96.8 & 71.1 \\
FS & 90.3 & 88.4 \\
FNAC + IC & 100.0 & 80.0 \\
IC + FS & 96.8 & 93.3 \\
FNAC + FS & 96.8 & 88.4 \\
FNAC + IC + FS & 100.0 & 93.3 \\
\hline
\end{tabular}

Values are expressed in percentages. There were 31 breast and 45 thyroid lesions. Samples were nondiagnostic in 1 breast FNAC, 4 thyroid FNAC and 1 thyroid FS and were excluded from statistical analysis.

nant lesions of the breast and thyroid is shown in table 4. For breast lesions, FNAC, IC and FS had an accuracy rate of 83.3, 96.8 and $90.3 \%$, respectively. The highest accuracy rate (100\%) was observed when FNAC and IC were taken together. For thyroid lesions, FNAC, IC and FS had diagnostic accuracy of $63.4,71.1$ and $88.4 \%$, respectively. The accuracy (93.3\%) was achieved when IC and FS were taken together. For thyroid lesions,

Med Principles Pract 1999;8:173-182 
FNAC, IC and FS had diagnostic accuracy of $63.4,71.1$ and $88.4 \%$, respectively. The accuracy $(93.3 \%)$ was achieved when IC and FS were taken together. False-negative cases due to FNAC in breast malignancies (4 cases) were due to misdiagnosis in 1 case and underinterpretation of malignant cells as atypical cells only or suspicious in the remaining 3 . False-negative cases in IOC (1 case) were due to misinterpretation of the malignant cells. False-negative cases in FS (2 cases) were attributed to difficulty in differentiating in situ ductal carcinoma from ductal hyperplasia in 1 case and misdiagnosis of carcinoma as inflammatory lesion in 1 case. In thyroid FNAC, false-negative cases ( 6 cases) were due to misinterpretation of follicular variant papillary carcinoma as follicular lesion in 2 cases, inadequacy of cell material for a confident diagnosis in 2 and absence of cell material representative of the occult malignancy in 2. In thyroid FS, false-negative cases (6 cases) were attributed to difficulty in interpreting the malignant growth due to freezing artifact in 2 cases, misdiagnosing follicular variant papillary carcinoma as follicular adenoma in 2 and inadequate sampling leading to missing of occult papillary carcinomas in the remaining 2 .

\section{Discussion}

During the recent years a number of studies have been published highlighting the combined utility of FNAC and FS in the diagnosis of thyroid nodules [2,3,14-17] and on the role of IC and/or FS in the diagnosis of thyroid or breast lesions [18-25]. To the best of our knowledge, our study is the first to evaluate the combined role of FNAC, IC and FS in the pre- and intraoperative diagnosis of breast masses and thyroid lesions.
According to Shaha et al. [2] intraoperative FS may help surgeons to distinguish between a benign and a malignant lesion, but as in FNAC, the major problem is the distinction between a follicular adenoma and follicular carcinoma. Intraoperative IC technique on the other hand is found to be superior to FS because freezing artifacts are avoided [11]. According to these authors, in the follicular variant of papillary carcinoma nuclear features such as intranuclear inclusions and grooves are more readily recognized in cytological smears than on FS. Shen et al. [26] have also reported on the successful diagnosis of follicular variant papillary carcinoma based on the examination of touch imprints similar to our technique. It is interesting that the 2 follicular variant papillary carcinomas encountered in our thyroid cases were diagnosed only by IC while they were missed by FNAC and FS or diagnosed as follicular neoplasm with no further specification. Costa and Sidawy [19] also found that intraoperative IC can help to detect those follicular lesions which are more likely to be neoplastic than nonneoplastic adenomatous nodules. Layfield et al. [3] found an inadequacy rate of $9 \%$ by FNAC and in $19 \%$ of the cases the FS was deferred to permanent section.

The overall diagnostic accuracy for exact categorization of benign and malignant lesions of the thyroid was highest for FS $(88.4 \%)$ followed by IC $(71.1 \%)$ and FNAC (63.4\%). The highest rate of accuracy (93.3\%) was achieved by IC and FS together.

In malignant lesions of the breast on the other hand, the sensitivity of IC was the best (95.8\%), and FS (91.7\%) and FNAC (82.6\%) closely followed it. The false-negative rate was also lowest with IC (4.1\%) compared to FS $(8.3 \%)$ and FNAC (17.4\%). Eskelinen et al. [27] found a sensitivity of $97.3 \%$ with FS, which is better than our result. The absence of false-positive diagnosis of malignancy yield- 
ing $100 \%$ specificity by all three techniques in our study is not unexpected and has been reported by several investigators previously $[17,22,25]$. False-negative results on the other hand as well as the variation in correct diagnosis by exact category remain to be a factor that will influence total diagnostic accuracy as seen in our results.

In exact categorization of benign and malignant lesions of the breast the highest rate of overall accuracy was achieved by IC (96.8\%) followed by FS (90.3\%) and FNAC (83.3\%). But when FNAC was combined with IC the overall diagnostic accuracy was $100 \%$. In a study comparing FS to IC in 206 surgical cases, Mair et al. [21] have achieved an overall diagnostic accuracy of $99.5 \%$ almost identical to our finding. They have also found IC to be superior to FS in most cases both in quality of material available to examination and in diagnostic accuracy. In our experience, IC material is almost always of superior quality to that of FS and FNAC. This is attributed to the fact that slide preparation is controlled and performed under vision unlike FNAC, which is a blind sampling technique. In addition, large portions of any lesion could be easily evaluated by IC in contrast to FS where small areas could be examined at any time. In a large series of ductal carcinoma in situ of the breast, Cox et al. [28] have utilized IC to eval- uate lumpectomy surgical margins for tumor extension. In their experience, lump margin IC could significantly decrease postoperative recurrence, decrease operative time and reduce the need for reexcision of incompletely removed lesions. The effect of interobserver variation on lesion interpretation has not been addressed in most published studies which compare IC, FNA and FS. In the present study, however, this source of variation is not a significant factor in the analysis since all four techniques were evaluated by the two investigators simultaneously.

Thus, in our experience these three techniques FNAC, IC and FS are complementary and supplementary to each other whenever any malignancy is detected by FNAC and then a definitive surgery can be undertaken based on cytology report. But when the diagnosis is benign, and a clinical suspicion persists, intraoperative IC and FS should be resorted to get the best diagnostic accuracy.

\section{Acknowledgment}

The authors wish to thank Dr. P.N. Sharma (Health Sciences Computer Center) for his assistance in the statistical analysis of data and Mr. James Luke for his secretarial help in the preparation of the manuscript.

\section{References}

1 Lowhagen T, Granberg P, Lundell G, Skinnari P, Sundblad R, Willems $\mathrm{J}$ : Aspiration biopsy cytology $(\mathrm{ABC})$ in nodules of the thyroid gland suspected to be malignant. Surg Clin North Am 1979;59:3-18.

2 Shaha AR, DiMaio T, Webber C, Jaffe BM: Intra-operative decision making during thyroid surgery based on the results of preoperative needle biopsy and frozen section surgery. Surgery 1990;108:964-967.
3 Layfield LJ, Mohrmann RL, Kopald $\mathrm{KH}$, Guiliano AE: Use of aspiration cytology and frozen section examination for management of benign and malignant thyroid nodules. Cancer 1991;68:130-134.

4 Layfield LJ, Glasgow BJ, Cramer H: Fine needle aspiration in the management of breast masses. Pathol Annu 1989;24:23-62.
5 Gardecki TM, Hogbin BM, Melcher DH, Smith RS: Aspiration cytology in preoperative management of breast cancer. Lancet 1980;ii:790792.

6 Bell DA, Hajdu SI, Urban JA, Gaston JP: Role of aspiration cytology in the diagnosis and management of mammary lesions in office practice. Cancer 1983;51:1182-1189. 
7 Wanebo HJ, Feldman PS, Wilhelm MC, Covell JL, Binns RL: Fine needle aspiration cytology in lieu of open biopsy in management of primary breast cancer. Ann Surg 1984; 199:569-579.

8 Strawbridge HTG, Bassett AA, Foldes I: Role of cytology in management of lesions of breast. Surg Gynecol Obstet 1981;152:1-7.

9 Norton LW, Davis JR, Wiens JL, Trego DC, Dunnington GL: Accuracy of aspiration cytology in detecting breast cancer. Surgery 1984;96:806814.

10 Silverman JF, Lannin DR, O'Brien $\mathrm{K}$, Norris HT: The triage role of fine needle aspiration biopsy of palpable breast masses: Diagnostic accuracy and cost effectiveness. Acta Cytol 1987;31:731-736.

11 Kontozoglou TE, Cramer HM: The advantages of intra-operative cytology: Analysis of 215 smears and review of the literature. Acta Cytol 1991;35:154-163.

12 Weintraub JA, Douglas CW, Gillings DB: Biostats: Data Analysis for Dental Health Care Professionals. Chapel Hill, Cavco, 1985, pp 1114.

13 Daly LE, Bourke GJ, McGilvary J: Interpretation and Uses of Medical Statistics. London, Blackwell Scientific Publications, 1991, pp 305308.

14 Bugis SP, Young JE, Archibald SD, Chen VS: Diagnostic accuracy of fine-needle aspiration biopsy versus frozen section of solitary thyroid nodules. Am J Surg 1986;152:411416.
15 Kopald KH, Layfield LJ, Mohrmann R, Foshag LJ, Giuliano AE: Clarifying the role of fine-needle aspiration cytologic evaluation and frozen section examination in the operative management of thyroid cancer. Arch Surg 1989;124:12011201.

16 Morosini PP, Mancini V, Filipponi S, Taccaliti A, Ferretti M, Cusella P, Vecchi A, Fianchini A, Fabris G: Comparison between the diagnostic accuracy in diagnosis of thyroid nodules with fine needle biopsy and intra-operative histological evaluation of frozen tissue. Minerva Endocrinol 1997;22:1-5.

17 Chang HY, Lin JD, Chen JF, Huang BY, Hsuch C, Jeng LB, Tsai JS: Correlation of fine needle aspiration cytology and frozen section biopsies in the diagnosis of thyroid nodules. J Clin Pathol 1997;50:1005-1009.

18 Esteban JM, Zaloudek C, Silverberg SG: Intra-operative diagnosis of breast lesions: Comparison of cytologic with frozen section techniques. Am J Clin Pathol 1987;88:681-688.

19 Costa MJ, Sidawy MK: Follicular lesions of thyroid: Intraoperative cytology. Mod Pathol 1989;2:521525.

20 Scopa CD, Melachrinou M, Apesson D, Bonikos D: Tissue imprints in surgical pathology: A rapid intraoperative diagnostic aid. Diagn Cytopathol 1990;6:5-8.

21 Mair S, Lash RH, Suskin D, Mendelsohn G: Intraoperative surgical specimen evaluation: Frozen section analysis, cytologic examination, or both? A comparative study of 206 cases. Am J Clin Pathol 1991;96:814.
22 Khanna AK, Singh MR, Khanna S, Khanna NN: Fine needle aspiration cytology, imprint cytology and trucut needle biopsy in breast lumps: A comparative evaluation. J Indian Med Assoc 1991;89:192-195.

23 De Rosa G, Boschi R, Boscaino A, Petrella G, Vetrani A, Palombini L, Pettinato G: Intraoperative cytology in breast cancer diagnosis: Comparison between cytologic and frozen section techniques. Diagn Cytopathol 1993;9:623-631.

24 Veneti S, Ioannidou-Mouzaka L, Toufexi H, Xenitides J, Anastasiadis P: Imprint cytology: A rapid, reliable method of diagnosing breast malignancy. Acta Cytol 1996;40: 649-652.

25 Scucchi LF, Di Stefano D, Cosentino L, Vecchione A: Value of cytology as an adjunctive intraoperative diagnostic method: An audit of 2,250 consecutive cases. Acta Cytol 1997;41:1489-1496.

26 Shen PU, Kuhel WI, Yang GC, Hoda SA: Intraoperative touch-imprint cytological diagnosis of follicular variant of papillary thyroid carcinoma. Diagn Cytopathol 1997; 17(1):80-83.

27 Eskelinen M, Collan Y, Puittinen J, Valkamo E: Frozen section diagnosis of breast cancer. Acta Oncol 1989;28:183-186.

28 Cox CE, Hyacinthe M, Gonzalez RJ, Lyman G, Reintgen D, Ku NN, Miller MS, Greenberg H, Nicosia SV: Cytologic evaluation of lumpectomy margins in patients with ductal carcinoma in situ: Clinical outcome. Ann Surg Oncol 1997;4:644649. 